$$
\begin{gathered}
\text { Yanbu Journal } \\
\text { of } \\
\text { Engineering } \\
\text { and Science }
\end{gathered}
$$

ISSN: 1658-5321
Vol. 2, April $2011(1432 \mathrm{H})$

www.yic.edu.sa/yjes

\title{
SURFACE FLOW GENERATION MECHANISM INDUCED BY A BUBBLE PLUME
}

\author{
Hassan Abdulmouti \\ Mechanical Engineering Department, Faculty of Engineering, Prince Mohammed University, Saudi Arabia \\ hassanabujihad@hotmail.com
}

\begin{abstract}
The technique of using a surface flow generated by the bubble plume is utilized as one of effective ways to control and collect the surface floating substances in naval systems, lakes, seas, rivers, oceans, as well as in various kinds of engineering processes handling a free surface. In the past, however, the detailed mechanism of the surface flow generation process has not been measured. The motivation of this paper is the demand to know the characteristics of the surface flow, which depends on the gas flow rate, the bubble size, and the internal two-phase flow structure of the bubble plume. In this paper, the twodimensional flow analysis based on Eulerrian-Lagrangian model and the particle tracking velocimetry measurement have carried out in order to elucidate the surface flow generation process in detail.

The present results explore that surface velocity profile can be predicted by EulerianLagrangian model in good agreement with experimental results. Maximum velocity of the surface flow increases as small bubble size is supplied. The surface flow is effectively generated in case of bubble plume compared to liquid jet flow because distortion point appears in the vicinity of surface. The data are obtained for two kinds of visualized images: the first that of the upper view of the surface flow, and the second that of the surface flow generation region under the free surface.
\end{abstract}

\section{KeYwords: Multiphase Flow, Bubble Plume, Surface Flow, Flow Visualization, Particle Imaging Velocimetry (PIV), Numerical Simulation, Eulerian- Lagrangian Model, Bubble, Free Surface}

\section{INTRODUCTION}

A bubble plume (which is one of typical bubbly flows) is observed in various engineering disciplines, e.g. in industrial, material, chemical, mechanical, and environmental applications. The following systems using the bubble plume were discussed in several literatures. Taylor [1] introduced that bubble-breakwaters were operated by means of a surface jet produced by a bubble plume. Jones [2] mentioned that prevention of clean surface of rivers or lakes from freezing over, oil pollution, and underwater-explosion damage were possible by using a bubble plume. Marks and Cargo [3] mentioned that bubble plumes were also available for keeping swimming areas free from slow-moving objects such as sea nettles. Another interest in bubble plumes arises in the consequences of context of rectifying oilwell blowout. Characteristically a lot of gas is emitted with the oil, and a plume develops due to the presence of bubbles formed from this gas. Mcdougall [4] explained that the extent of damage caused by an oil-well blowout was strongly dependent on whether all the oil rises straight to the surface or some 
of it spreads out horizontally at some intermediate depth. Hara et. al. [5, 6] measured two dimensional surface flow velocity profiles using hot wires as a basic study for preventing oil diffusion due to the bubble plume. Moreover, the surface flow generated by bubble plume is considered as a key phenomenon in modern industries, such as metal refinement $[7,8]$, future-type nuclear power plants [9], prevention of surface sloshing in furnaces, removal of oxide film or impurity which is floating on the surface of the chemical reactor or metal refining furnaces in order to maintain the performance of reaction. These processes require the control of the concentration and transportation of surface floating substances, solidized materials or impurities, as well as to stabilize the motion of the interface itself in order to warrant their designed performances. The main features of these kind of flows are the following: 1) A large scale circulation of the liquid phase can be generated in circulation systems like lakes, agitation tanks, etc. 2) Strong rising flows can be induced by the pumping effect as in air-lifting pumps. 3) High speed surface flows are developed at the free surface, to control the accumulation and the transportation of the surface floating substances. 4) A high turbulence energy can be produced in the two-phase region due to the strong local interaction between individual bubbles and surrounding liquid flow.

On the other hand, the improvement and development in the performance of oil barriers (oil fences) are required especially for high values of current velocity, wave height and wind velocity in order to protect the environment and the naval plants from oil pollution. Hence, a bubble plume is considered to possibly be an effective way to control the accumulation and transportation of surface-floating substances. It is also expected to be an effective tool to support the function of an oil fence since it can generate a strong and wide surface flow over the bubble generation system, and it can damp the wave motion. Many researchers have carried out extensive model experiments by focusing on the flow field using air bubbles because gas injection through a bottom nozzle is the most popular and has wide applications. Since bubble plumes have been used with varying degrees of success more information on the mentioned above subjects should be accumulated [10-24].

Conventional research regarding the surface flow was mainly conducted in order to know the approximate relationship between the gas flow rate of the bubble plume and the surface flow velocity. (a) The relationship between gas flow rate and liquid flow rate, was measured by Hussain \& Siegel [17], Leitch \& Baines [19]. (b) Generation and restriction of turbulence due to bubbles, was studied by Alam \& Arakeri [25] and Iguchi et. al. [26]. The following points were investigated in our earlier paper: 1) The technique mechanism of using the surface flow generated by a bubble plume in damping the wave motion (the wave damping effects of the surface flow). 2) The flow pattern around the bubble plume. 3) The calculation of the altitude $\Delta \mathrm{h}$ of the upheaval bulge of the two-phase stratified liquid interface, which is induced by a bubble plume. 4) The bubbling convection patterns in immiscible two-phase stratified liquids. 5) The mixing effects $[10,22,23]$. However, detailed discussion was not done concerning the surface flow generation process (fundamental characteristics of the surface flow generation mechanism which is induced by the bubble plume), which depends on twophase flow structure in the vicinity of the surface. Also, the influence of bubble size has 
not been clarified yet. Hence, there is still possible improvement to get higher efficiency for generating the surface flow.

This paper is concerned with the characteristics of the surface flow (the detailed structure of surface flow generation mechanism), which depends on the gas flow rate, the bubble size, and the internal twophase flow structure of the bubble plume. Particle Imaging Velocimetry (PIV) including Particle Tracking Velocimetry (PTV) and numerical simulation model using EulerianLagrangian model (E-L model) [11] are applied after carrying out two kinds of flow visualization in order to evaluate their parameter relationships. The first one is for the upper view of the surface flow, and the second that of the surface flow generation region under the free surface which is the location or the region where the bubble rise velocity was measured. It is confirmed by this paper that the experimental results resemble the numerical results. The relationship between the maximum surface flow velocity and the bubble generation condition in the surface flow generation process is explained.

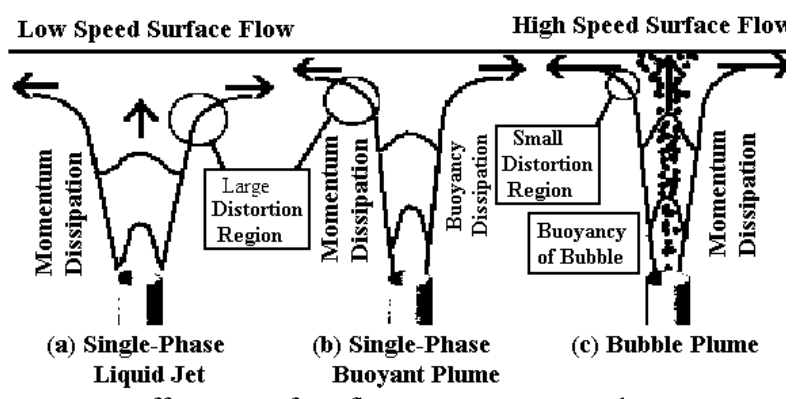

Fig.1. Different surface flow generation mechanisms

In fact, the main reason for surface flows induced by bubble plumes to be utilized in so many fields mentioned above is the simplicity of installation. However, from the fluid mechanical point of view, it is important to focus on the advantages of the bubble plume comparing to various other types of jet flows. As an example, Fig. 1 shows schematic figures of three types of the jet flows: 1) Single-phase liquid jet flow (water jet flow), where the maximum velocity in the jet decreases monotonically due to turbulent momentum diffusion, so that the width of the jet expands near the surface. The resultant thick layer surface flow will have a low velocity. 2) Single-phase buoyant jet flow, where the maximum velocity peak is flattened by the buoyancy effect. However, the buoyancy is dissipated due to turbulent mixing near the free surface so that no thin high speed surface flow occurs. 3) On the contrary, the bubble plume induced flow keeps its initial buoyancy even close to the surface since bubbles do not diffuse immediately (it is called immiscible buoyant jet). Furthermore, an individual bubble has motion characteristics different from surrounding liquid, therefore, the buoyancy distribution does not simply diffuse. The resultant surface flow is thinner and faster than in the first two cases. Hence, the surface flow is rather effective in case of the bubble plume compared to the first two flows because the distortion point occurs near the surface.

\section{EXPERIMENTAL METHOD AND CONDITIONS}

Figure 2 shows schematic diagram of the experimental apparatus. The inner tank size is $1800 \mathrm{~mm}$ in length, $800 \mathrm{~mm}$ in height, and $200 \mathrm{~mm}$ wide, made of transparent acrylic resin. The water in the tank is $\mathrm{H}=600 \mathrm{~mm}$ high. The experimental and simulation conditions are listed up in Table 1 to be similar to real applications. Although the experiments are performed in relatively shallow water $(\mathrm{H}=600 \mathrm{~mm})$ but the results are applicable for typical applications involve in larger depths. Hence, these results can be transferred directly to realistic cases. The bubble generator is made of rectangular porous material, installed at the center of the bottom part of the tank. The injector surface 
of the bubble generator is the area $A=(180 \times 100) \mathrm{mm}$. Three injector nozzles are arranged for the bubble generator as shown in Table 2. The gas flow rate is precisely controlled by a pressure regulator and a flowmeter. A lighting setup with a black background and metal halide lamps is used for taking the images. The visualized flows of the surface (upper side of the tank Fig. 2) are recorded by a digital video camera (Sony, DCR-VX1000) that captures 30 fps. While the images of the internal flow structures are captured by a high speed video camera with 400 fps. The digital images are preprocessed through the NIH image software version 1.60 (produced by the National Institutes of Health of the United States of America). The preprocessing entails sharpening, binarizing and smoothing of the images. The bubble injector conditions are shown in Table 2. The values in this table are calculated by using the time average of 120 consecutive frames in the image processing (4 seconds). The averaged bubble diameter and the standard deviation are calculated by measuring more than 1200 bubbles in the local VTR images in the bubble plume using image processing. These images are taken by recording local pictures of the injector region of the bubble generator.

The relative velocity between the bubbles and the liquid flow corresponds well to the terminal rising velocity of the bubble in a quiescent liquid; especially in the area of measurement since bubbles do not receive a strong pressure gradient force because all the free surface has atmospheric pressure as will be explained in later section. The pressure force is transmitted to a bubble via the liquid phase motion surrounding the bubble. It does not play important roles for the internal flow structure. Therefore, the effect of the static pressure reduction on the bubble rise is ignored as it will not affect the bubble diameter in the area of measurement. In other word, since the volumetric change of a bubble due to a pressure fluctuation or to a pressure gradient in the flow field does not affect the translational motion of the bubble, hence, the volume of the rising bubble is assumed constant in the flow field. The bubble diameter is defined by the equivalent bubble diameter using ellipsoidal approximations for the bubble shapes. The equivalent bubble diameter is estimated by the vertical and the horizontal lengths of each bubble, which are obtained by using the NIH software after binarizing the images. The measurement uncertainty (standard deviation) for the bubble diameter is estimated to be around (0.01 to $0.015 \mathrm{~mm}$ ) of the averaged bubble diameter according to the pixel resolution. The void fraction $(\alpha)$ is calculated by using the equation $\left(\alpha=Q_{g} / A \times V_{b}\right)[10,20,22,23,28$, 29], where $A$ is the area of calculation in the injector region, (injector surface of the bubble generator $), A=(180 \times 100) \mathrm{mm}, V_{b}$ is the rising bubble velocity. The measurement uncertainty for the void fraction is estimated to be about $2 \%$. The bubble rise velocity is unsteady at the beginning (at the nozzle exit) and after a short period of time it reaches the terminal rise velocity. The measurement uncertainty for the rising bubble velocity is estimated to be about $2 \%$.

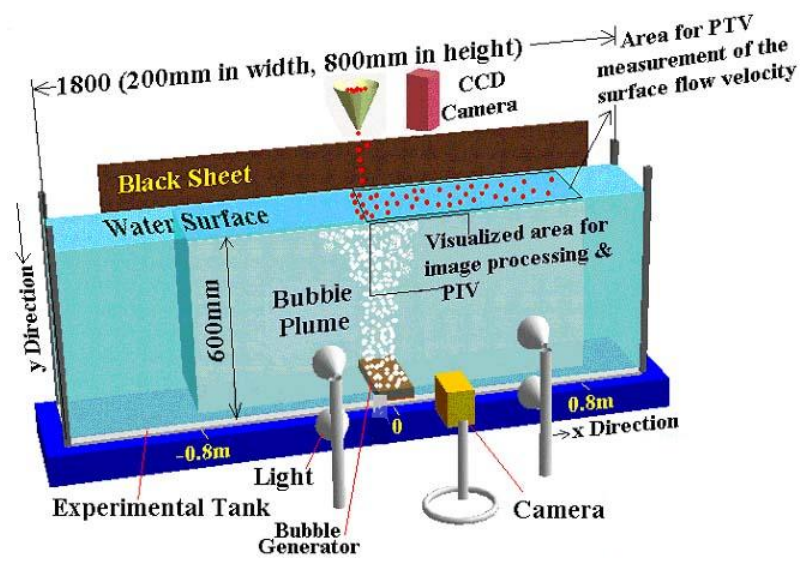

Fig. 2. Schematic diagram of experimental setup 
TABLE 1: EXPERIMENTAL AND SIMULATION CONDITIONS

\begin{tabular}{|c|c|}
\hline Parameter & Value \\
\hline Density of water & $\rho=1000 \mathrm{~kg} / \mathrm{m}^{3}$ \\
\hline Kinematic viscosity of water & $\mathrm{v}=10^{-6} \mathrm{~m}^{2} / \mathrm{s}$ \\
\hline $\begin{array}{c}\text { Initial water height (without } \\
\text { bubble) }\end{array}$ & $\mathrm{H}=600 \mathrm{~mm}$ \\
\hline $\begin{array}{c}\text { Atmospheric pressure on the } \\
\text { surface }\end{array}$ & $101 \mathrm{kPa}$ \\
\hline Temperature of environment & $15-20^{\circ} \mathrm{C}$ \\
\hline Maximum gas flow rate & $20.0 \times 10^{-5} \mathrm{~m}^{3} / \mathrm{s}$ \\
\hline Density of gas (air) & $1.25 \mathrm{~kg} / \mathrm{m}^{3}$ \\
\hline
\end{tabular}

TABLE 2: EXPERIMENTAL CONDITIONS FOR BUBBLE GENERATOR

\begin{tabular}{|c|c|c|c|}
\hline \multirow[t]{2}{*}{$\begin{array}{l}\text { Gas volume flow } \\
\text { rate } Q_{g}\left[\mathrm{~m}^{3} / \mathrm{s}\right]\end{array}$} & \multicolumn{3}{|c|}{$\begin{array}{c}\text { Mean bubble diameter D }(\mathrm{mm}) \& \\
\text { Void fraction } \alpha\end{array}$} \\
\hline & Nozzle-1 & Nozzle-2 & Nozzle-3 \\
\hline \multirow[t]{2}{*}{$\mathrm{Q}_{\mathrm{g} 1}=0.167 \times 10^{-4}$} & $\begin{array}{c}\mathrm{D}=2.00, \\
\alpha=0.0011\end{array}$ & $\begin{array}{c}D=3.05, \\
\alpha=0.0024\end{array}$ & $\begin{aligned} D & =4.12, \\
\alpha & =0.0046\end{aligned}$ \\
\hline & [Case-1a] & [Case-1b] & [Case-1c] \\
\hline \multirow{2}{*}{$\mathrm{Q}_{\mathrm{g} 2}=0.833 \times 10^{-4}$} & $\begin{array}{c}D=5.00, \\
\alpha=0.0123\end{array}$ & $\begin{array}{c}D=6.09, \\
\alpha=0.0195\end{array}$ & $\begin{array}{c}D=7.10 \\
\alpha=0.0267\end{array}$ \\
\hline & [Case-2 a] & [Case-2 b] & [Case-2 c] \\
\hline \multirow[t]{2}{*}{$\mathrm{Q}_{\mathrm{g} 3}=1.670 \times 10^{-4}$} & $\begin{array}{c}D=8.00, \\
\alpha=0.0379\end{array}$ & $\begin{array}{c}D=9.10, \\
\alpha=0.0598\end{array}$ & $\begin{array}{c}D=10.20, \\
\alpha=0.0605\end{array}$ \\
\hline & [Case-3 a] & [Case-3 b] & [Case-3 c] \\
\hline
\end{tabular}

Our observation showed that the particles and the bubbles have an almost two-dimensional motion (in $x-y$ plane for the internal flow structure and $\mathrm{x}-\mathrm{z}$ plane for the surface flow) except a tiny degree of three-dimensional fluctuations due to turbulence. The time averaged flow is almost two-dimensional especially because there are no perpendicular components to the front and back walls in the time averaged flow field for the internal flow structure. This kind of two-dimensional experiment for multiphase flows is a frequent subject treated in many research literatures
$[10,14,22,23,24,28,30,31]$. Therefore, the two-dimensional measurements with PIV are applicable for grasping the time-averaged internal flow structure and time averaged surface flow velocity.

\section{1. EXPERIMENTAL MEASUREMENTS OF THE SURFACE FLOW VELOCITY}

The surface flow generated by a bubble plume has a maximum velocity on the free surface. Hence, the velocity of the surface flow is directly measured by using tracer particles. When the surface flow is visualized, spherical particles made of polystyrene foam, $1.5 \mathrm{~mm}$ in diameter and a density of $50 \mathrm{~kg} / \mathrm{m}^{3}$, are used as tracer particles for the PTV measurement (to measure the surface flow velocity). Even though the density of these particles is different from the density of the liquid, we can consider these particles and the liquid to have the same velocities on the liquid interface. Because, the velocities of both the particles and the surface flow do not involve high frequency components which could enhance the time-lag of the particle motion. These particles float on the free surface and follow the surface flow. According to the observation, $30 \%$ of the particle is under the surface. In this case, the traceability of the floating particles against the surface flow velocity is theoretically estimated by using the equations of translational motion of spherical particle. In the equations, the inertial force of the particle, the drag forces from liquid and gas phases, the pressure gradient force, and the added inertial forces from the two phases are considered. Each force component, which depends on the driftlevel of the floating particle, is linearly approximated by the drift-level parameter. In our observation, the drift-level is around $1 / 3$ of the particle diameter. Using this estimation, it has been confirmed that the floating 
particles sufficiently follow the surface flow. The result warrants $99.5 \%$ of the velocity amplitude ratio when the frequency $(\mathrm{f}=\omega / 2 \pi)$ of the fluctuation velocity is lower than $50 \mathrm{~Hz}$. Although, a small velocity disturbance is caused by individual bubble collapse at the surface, the velocity fluctuation however is statistically isotropic so that the resultant time-averaged velocity profile is not affected by the velocity disturbance. Furthermore, the few bubbles, which are not broken on the surface, will not have strong velocity fluctuation, there is no interference with the motion of the particles.

The images are ported to a computer and the time-averaged velocity vector maps are obtained by using the BICC (Binary Image Cross-Correlation) method [32, 33, 34]. After capturing 30,000 velocity vectors of the surface flow during 10 seconds $(\mathrm{N}=300$ frames of the images). The time-averaged profile of the surface flow velocity in the $\mathrm{x}$ direction is obtained for different cases of experimental conditions as shown in Fig. 3. Where the upper figure (a) is an example of an instantaneous PTV measurement results for case-2b, and the bottom figure shows the experimental results for the time averaged surface flow velocity profiles. The time averaged velocity of the surface flow in the $\mathrm{x}$ direction is calculated by equation (1).

$\overline{\mathrm{U}}=\frac{1}{\mathrm{~N}} \sum_{\mathrm{i}=1}^{\mathrm{N}} \mathrm{U}_{\mathrm{i}}$

Where $N$ is the number of the calculated velocity vectors maps (about 300 maps), each map is divided into small areas according to the $\mathrm{x}$ direction, $U_{i}$ is the average of the velocity vectors for each small area. $\bar{U}$ is the time average velocity of the same area taken for the $\mathrm{N}$ maps. In each small cell, around 300 velocity vectors were captured and used to calculate the average velocity. Figure 3 shows that the velocity of the surface flow is zero at the point where the flow changes its orientation from vertical into horizontal. Since the particles start to move from this point toward the tank wall, their velocity increases from zero till it reaches a certain value, which will be the constant velocity during the particles movement toward the tank wall.

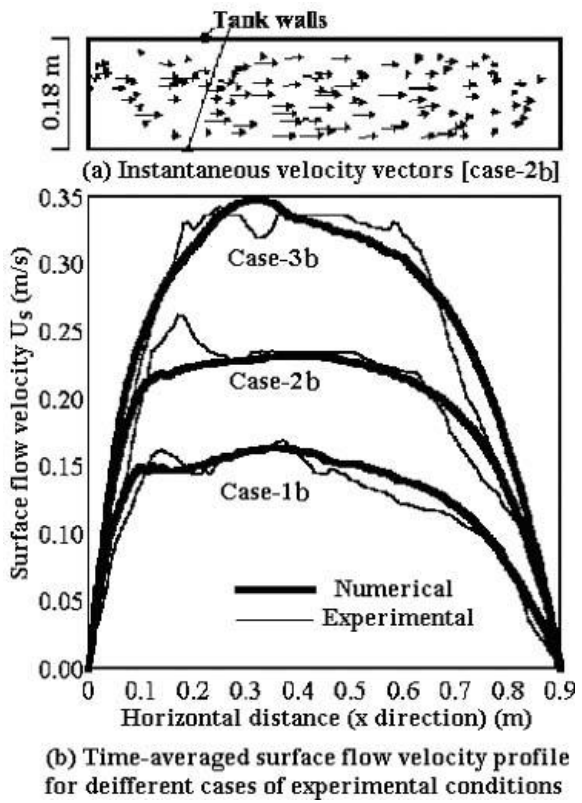

Fig. 3. Comparison between numerical results and experimental results for the time averaged surface flow velocity profiles

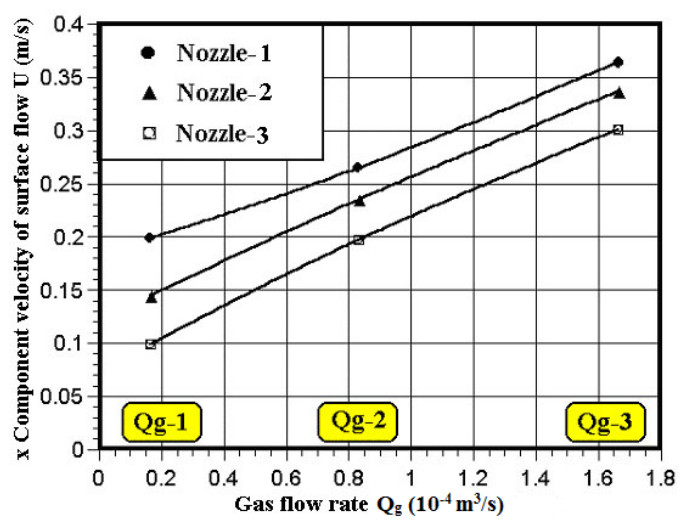

Fig. 4. Time-averaged maximum surface velocity for nine experimental conditions (The effect of the bubble size on the surface flow velocity in the $\mathrm{x}$ direction)

To summarize the above results, the relationship between the time-averaged maximum surface velocity and the gas flow rate is shown in Fig. 4. This figure shows the effect of the bubble size on the time averaged 
surface flow velocity for the nine experimental conditions.

According to a previous study by (Bains and Leitch ) [35], the volume flow rate of the liquid pumped by the bubble plume is proportional to the gas flow rate with a power index of 0.3 to 0.5 . On the other hand, the power indexes of the gas flow rate and bubble diameter for the maximum surface velocity are calculated using the present data, based on a least square method (LSA). The power index of the gas flow rate obtained is ranging from 0.25 to 0.50 . This value is almost the same as that of the liquid volume flow rate. This means that the increase of the surface flow velocity corresponds to the increases of liquid volume flux pumped by the bubbles. On the contrary, the power index of the bubble diameter for surface flow velocity in the case of the lowest gas flow rate is -0.75 , and in the case of the highest gas flow rate is -0.25 .

\section{2. EXPERIMENTAL MEASUREMENTS OF THE INTERNAL FLOW STRUCTURE}

In order to elucidate the surface flow generation process in detail, the flow is visualized and a PIV measurement of the internal flow under the free surface is performed. First, spherical particles made of a high-porous polymer with diameters of 200 to $600 \mu \mathrm{m}$ and a density of $1010 \mathrm{~kg} / \mathrm{m}^{3}$, are used as tracer particles for the PIV measurement of the internal liquid flow under the surface. These particles are seeded in the entire tank volume, and then illuminated through direct lighting. The recorded images contain distributed particles and bubbles. By using an image-separation algorithm, which was explained in our earlier paper [10], the particle image and the bubble image are extracted from the original image. By testing this method on 125 frames, it is in fact confirmed that the ratio of correctly captured particles is more than $98 \%$. After obtaining the time series of both particle images and bubble images, the velocity vector distributions for both separated images of particles and bubbles are calculated for 125 frames by using the BICC (Binary Image Cross-Correlation) algorithm [32, 33, 34]. In this part of our paper, the horizontal direction is considered to be the $\mathrm{x}$-direction, and the $\mathrm{y}$ direction is the vertical direction centered in the bubble plume. The point of origin of the $\mathrm{x}, \mathrm{y}$ coordinate system is located at the center of the bubble plume at the free surface. Figure 5 shows the time-averaged velocity vectors of the particles (for case-1c of the experimental conditions), which represent the liquid flow. Since the averaged flow field is symmetric, only a half domain is drawn for all figures. These results are obtained by using more than 20,000 velocity vectors, which are captured during the 125 consecutive image frames.

Furthermore, two methods are used to obtain these results (or to get the rearranged vector map). The first one is the grid averaging method, which is used in order to get the grid rearranged vector map as shown in Fig. 5 (a). The second method is the so-called LER (Laplace Equation Rearrangement) method $[36,37]$ as shown in Fig. 5 (b). The timeaveraged velocity vector map is calculated by using both the grid averaging method and the LER method in order to detect the methoddependence of the averaged results. The two kinds of time-averaged maps show no remarkable discrepancy. This is because LER provides a correlation coefficient of over 0.98 between real and reconstructed flow fields especially if the number of the velocity vectors is very large like in our case. Therefore, the two figures are very similar and yield almost the same results. Moreover, the results, which are obtained and calculated later by using the two methods, have almost no discrepancy e.g. (the two-dimensional distribution of the 
specific kinetic energy, the two-dimensional components of the vorticity distribution, the shear strain rate distribution and the shear stress $\left.\left[\tau_{\mathrm{yz}}=\mu \partial \mathrm{v} / \partial \mathrm{x}\right]\right)$. On other words, the two methods again give almost the same results.

The time-averaged velocity vectors map of the liquid phase (Fig. 5 (a) and (b)) shows that the main upward liquid flow is driven along the bubble plume by rising bubbles. The momentum of the upward flow becomes maximum near the free surface. Just under the free surface the upward flow changes its orientation rapidly into a horizontal flow. It is also recognized that as the gas flow rate increases, the magnitude of velocity increases and the effective area of the bubble plume (the width of the surface flow) expands in horizontal direction. Beyond that, the rapid distortion of the liquid phase results just under the free surface. This is qualitatively different from (not found so clearly in) the case of a single-phase liquid jet flow whose speed is equivalent to the bubble plume. This is because, for the bubble plume, the liquid phase is continuously accelerated up to the free surface by bubbles in the vertical direction, while it is only dissipated in the case of a single-phase liquid jet flow. Hence, in case of single-phase liquid jet flow the liquid velocity just near the free surface is not sufficient to generate a high speed surface flow. The merit of using bubbles for generating the surface flow is indicated by the location with the highest distortion rate in the liquid phase, i.e., it stays in the vicinity of the free surface while it will appear at a deeper position in the cases of a vertical jet flow or a single-phase buoyant jet.

Moreover, the time averaged velocity vector map of the bubbles is obtained using a grid averaging methods as shown in Fig. 6. These results are obtained by using more than 20,000 velocity vectors, which are captured during 125 consecutive image frames. It is confirmed by the data that the relative velocity between the bubbles and the liquid flow corresponds well to the terminal rising velocity of the bubble in a quiescent liquid.

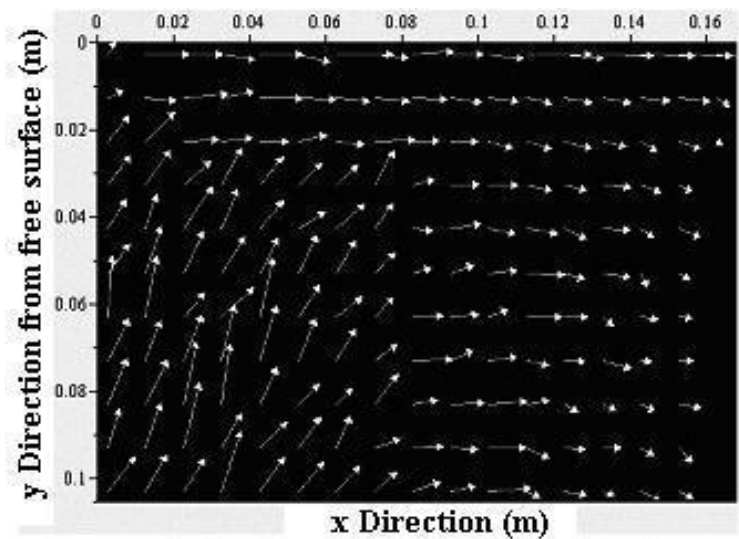

a) Grid-rearranged Method

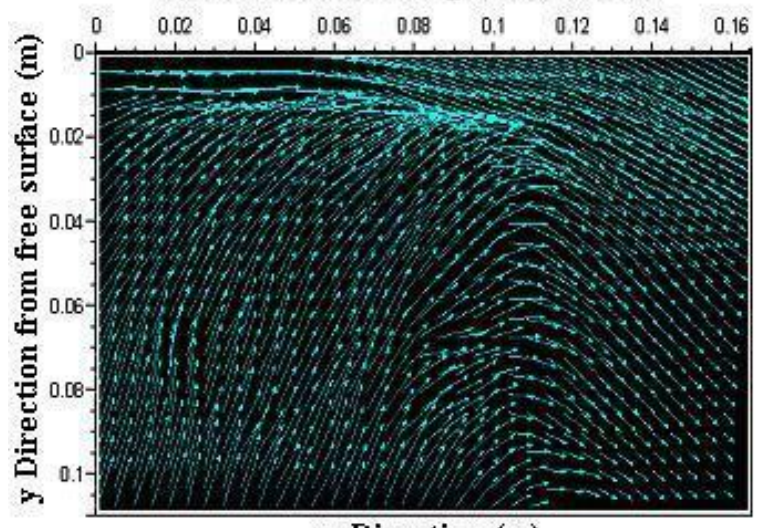

x Direction (m)

b) LER Method

Fig. 5. Time-averaged velocity vector map of liquid phase under free surface obtained by PTV

In other word, the rising velocity corresponds well to the sum of liquid velocity and terminal slip-velocity. This result indicates that the bubble motion itself is only strongly governed by the balance between the buoyant and the drag forces near the free surface.

The dynamic pressure gradient force, added inertial force, and the other force components do not play important roles for the internal flow structure. This characteristic is one of the differences to an impinging jet flow on a solid wall, in which the dispersion experiences strong pressure gradient force. If the flow field 
would be like an impinging jet on a wall, the bubble velocity would vary due to the pressure gradient caused around the impinging region. But, in this case, the bubbles do not receive a strong pressure gradient force because all the free surface has atmospheric pressure.

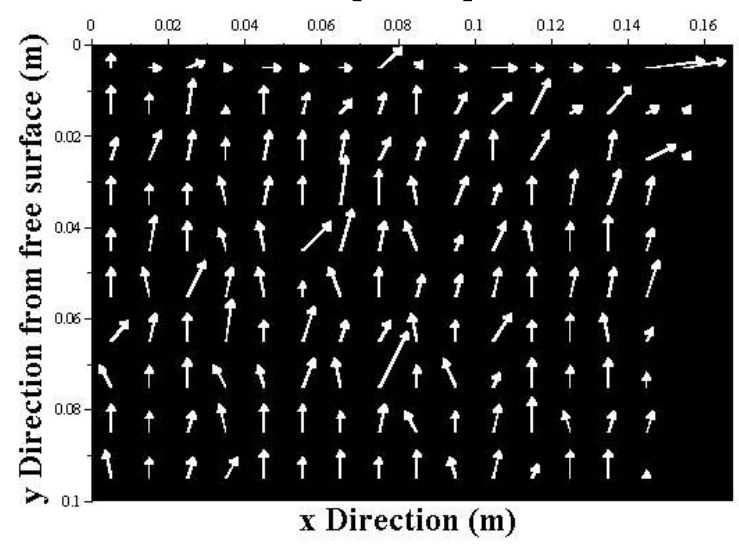

Fig. 6. Time averaged bubble velocity

In order to clarify the details of the internal flow structure, the two-dimensional distribution of the kinetic energy is calculated from the measured averaged velocity vector map of the particles as shown in Fig. 7. It can be confirmed from this figure that the highest kinetic energy is generated in the center of the bubble plume and in the vicinity of the surface interface where the flow changes its orientation from vertical into horizontal direction in the area of the surface flow $(\mathrm{x}=0$ to $0.03 \mathrm{~m}$ and of $\mathrm{y}=0$ to $0.055 \mathrm{~m}$ ).

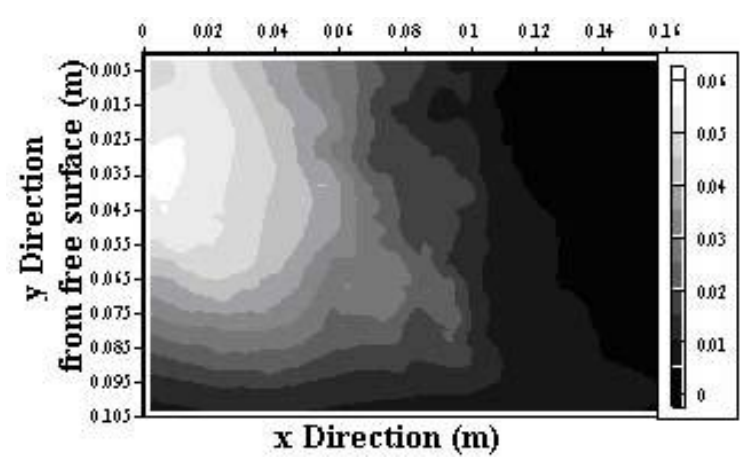

Fig. 7. Kinetic energy distribution of liquid phase under free surface $(\mathrm{m} / \mathrm{s})^{2}$
Moreover, the two-dimensional components of the vorticity distribution, the shear strain rate distribution and the shear stress $\left(\tau_{\mathrm{yz}}=\mu \partial \mathrm{v} / \partial \mathrm{x}\right)$ are derived and calculated from the measured averaged velocity vector map of the liquid as shown in Fig. 8, Fig. 9 and Fig. 10 respectively.

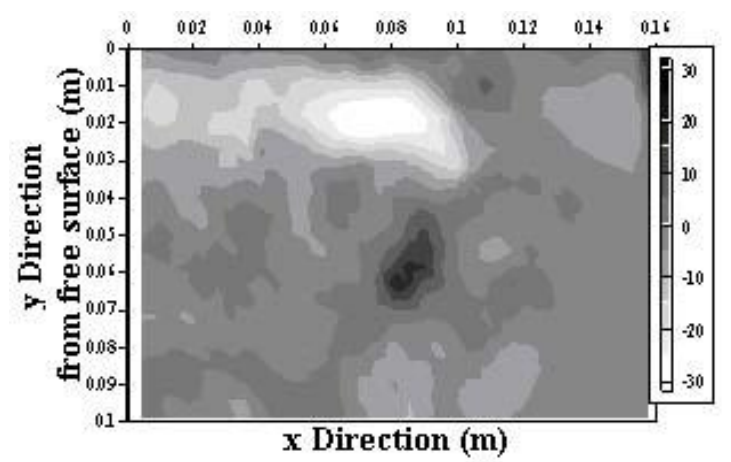

Fig. 8. Vorticity distribution of liquid phase under free surface $\left(s^{-1}\right)$

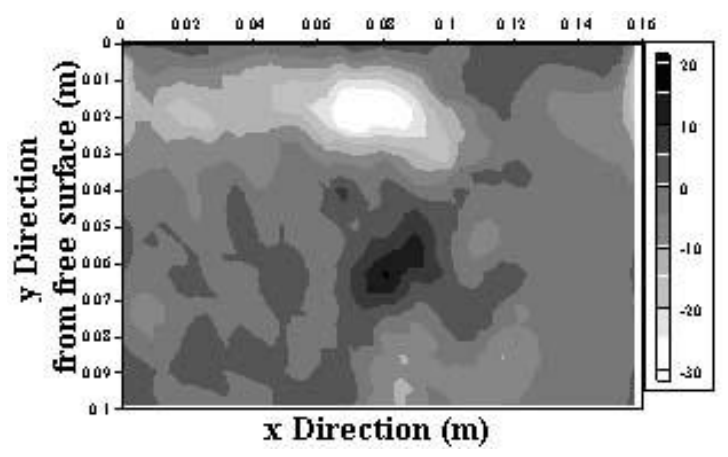

Fig. 9. Shear strain rate distribution of liquid phase under free surface $\left(s^{-1}\right)$

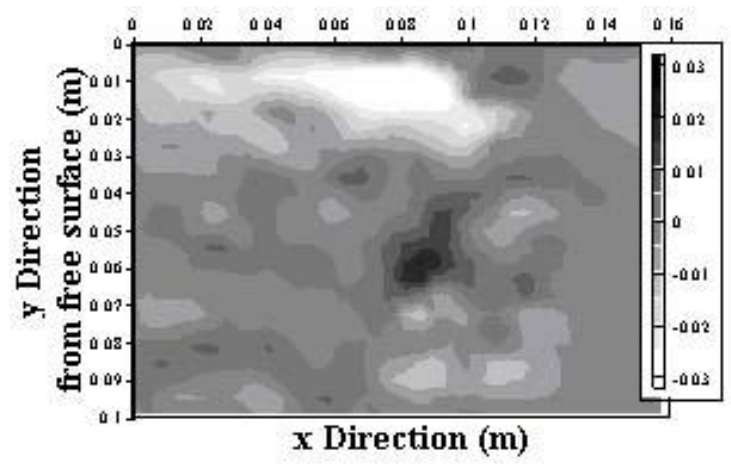

Fig. 10. Shear stress of liquid phase under free surface $(\mathrm{Pa})$ $\tau_{y z}=\mu \partial v / \partial x$ 


\section{EXPERIMENTAL RESULTS}

(1) It is recognized from Fig. 3 that the surface flow velocity rapidly increases in the bubble plume region $(x<0.2 \mathrm{~m})$, keeps nearly constant over a certain distance $(x<0.6 \mathrm{~m})$, and decreases close to the end wall $(0.6 \mathrm{~m}<\mathrm{x}$ $<0.9 \mathrm{~m})$. Also, larger gas flow rates cause higher surface flow velocities.

(2) It is clear from Fig. 4 that the surface flow velocity increases with the gas flow rate. Also, it is remarkably enhanced when smaller bubbles are generated. Moreover, the data indicate that the smaller the bubbles the faster the induced the surface flow velocity. Also, the bubble size is a very important factor in the case of lower gas flow rates. This is because larger bubbles rise fast up to the free surface when there are few bubbles around it. This means that the period of momentum exchange between the two phases becomes short.

(3) The results in Fig. 5 indicate that a surface flow is more effectively generated by means of bubbles than by a liquid jet flow because the distortion point appears in the vicinity of surface.

(4) The observation in Fig. 7 implies that the surface flow induces the largest kinetic energy. Beyond that, a large kinetic energy loss of the surface flow takes place in the center of the bubble plume of the free surface around the point $(x=0.1, y=0.0)$. Then the energy loss decreases from this point $(x=0.1, y=0.0)$ onwards till the point $(\mathrm{x}=0.16, \mathrm{y}=0.0)$ in the horizontal direction parallel to the $\mathrm{x}$ direction. This confirms the fact that the bubble plume can generate a strong and wide surface flow over the bubble generation system.

From figures 8, 9 and 10 the following issues are drawn:
(5) The liquid phase flow changes its orientation from vertical to horizontal direction in the vicinity of the free surface. A rapid distortion takes place in the area of $\mathrm{x}=$ 0.06 to $0.09 \mathrm{~m}$ and of $\mathrm{y}=0.01$ to $0.03 \mathrm{~m}$.

(6) The surface flow is rapidly accelerated in the initial region of $\mathrm{x}=0$ to $0.05 \mathrm{~m}$, due to the continuous supply of liquid from the bubble plume. This result corresponds well to other measurement results shown in Fig. 3.

(7) The thickness of the surface flow is about $0.02 \mathrm{~m}$.

(8) The width of the upward flow induced by the bubble plume is larger than the thickness of the surface flow. The minimum thickness is around $0.01 \mathrm{~m}$.

(9) The highest shear stress and the highest shear strain are generated by the surface flow which is induced by the bubble plume. They appear in a layer under the free surface. Therefore, it can be concluded that the initial surface flow is rapidly generated in this layer.

(10) High vorticity is generated in a layer under the free surface. This layer rapidly changes the orientation of the liquid flow from the vertical to the horizontal direction.

\section{NUMERICAL SIMULATION METHOD}

The Eulerian-Lagrangian model [20] is adopted in this paper because it was confirmed to have higher resolution in time and space since it directly compute individual bubble diameters, positions, and velocities [20]. The following assumptions are employed in order to formulate the governing equations: (1) The bubble size is much smaller than the characteristic length scale of the flow field. (2) The bubbles are spherical as explained in experimental paragraph. (3) Coalescence, fragmentation and mutual interaction between bubbles are ignored. (4) 
There is no mass transfer on the gas-liquid interface; therefore, the amount of gas inside a bubble is constant as explained in the experimental measurement. (5) The flow field is isothermal. These assumptions were applied and explained in earlier papers $[38,39,40,41$, $42,43,44,45,46]$.

\section{a) Governing Equations:}

Under the above mentioned assumptions, the governing equations can be formulated as follows:

- Mass Conservation Equation for the Liquid Phase:

$\frac{\partial f_{L} \rho_{L}}{\partial t}+\nabla \cdot\left(f_{L} \rho_{L} u_{L}\right)=0$

where, $f_{L}$ is the liquid volume fraction, $\rho_{L}$ is the density of the liquid, $t$ is the time, and $u_{L}$ is the liquid velocity vector.

- Restriction on the Two Volume Fractions:

$f_{\mathrm{L}}+f_{\mathrm{G}}=1$

where, $f_{G}$ and $f_{L}$ are the gas and the liquid volume fractions, respectively. $f_{G}$ is given by Eq. 4:

\section{-Gas volume fraction}

$f_{G}=\frac{1}{V} \int f_{\text {GLocal }} d V$

where, $V$ is the averaging volume of a grid element, $f_{\text {Glocal }}$ is the phase indicator, i.e., $\mathrm{f}=1$ in the gas phase and $\mathrm{f}=0$ in the liquid phase. $f_{\text {Glocal }}$ is calculated by the TD method [47].

-Bubble Tracking Equation

$x_{G}=x_{G 0}+\int_{0}^{t} u_{G}(t) d t$

where $x_{G}$ is the position vector of the bubble center of gravity, $\boldsymbol{x}_{G o}$ is its initial value, and $u_{G}$ is the translational velocity vector of the bubbles.

- Momentum Conservation Equation for all Phases

$$
\begin{gathered}
\frac{\partial f_{L} \rho_{L} u_{L}}{\partial t}+\nabla \cdot\left(f_{L} \rho_{L} u_{L} u_{L}\right)+\frac{\partial f_{G} \rho_{G} u_{G}}{\partial t} \\
+\nabla \cdot\left(f_{G} \rho_{G} u_{G} u_{G}\right) \\
=-\nabla P-\left(f_{L} \rho_{L}+f_{G} \rho_{G}\right) g+\left(F_{L L}+F_{G G}\right)
\end{gathered}
$$

where, $p$ is the pressure in the liquid phase. $\mathrm{g}$ is the gravitational acceleration. $F_{L L}$ and $F_{G G}$ are the shear stress in each phase and given for continuous phase components as:

$F_{L L}=\nabla \cdot \mu\left[\nabla u_{L}+\left(\nabla u_{L}\right)^{T}-\frac{2}{3}\left(\nabla \cdot u_{L}\right) I\right]$

We set $F_{G G}=0$. The viscosity is given by the effective viscosity of bubbly flows [48]: $\mu=\left(1+f_{G}\right) \mu_{\mathrm{L}}$. This equation is valid for small Reynolds numbers less than 1; however, there is no general equation for higher Reynolds numbers so that this description is adopted as a first order approximation.

-Translational Motion Equation for a Bubble:

$\frac{d}{d t}\left(\rho_{G} V_{G} u_{G}\right)+\frac{d}{d t}\left(\beta \rho_{L} V_{G} u_{G}\right)-$

$\frac{D L}{D t}\left(\beta \rho_{L} V_{G} u_{L}\right)+\rho_{G} V_{G} g+V_{G} \nabla P-$

$V_{G} \mu\left[\nabla^{2} u_{L}+\frac{1}{3} \nabla\left(\nabla \cdot u_{L}\right)\right]+$

$\frac{1}{2} \rho_{L} \pi r_{G}^{2} C_{D}\left|u_{s}\right| u_{s}+\frac{1}{2} \rho_{L} V_{G} u_{S}\left(\nabla \cdot u_{L}\right)=0$

Many forces act on a bubble in a liquid flow, which is non-uniform and unsteady. These forces are: self inertia force, added inertia force, pressure force, viscous force, drag force, lift force, force of gravity, and history force. Here, the pressure and the viscous forces are transmitted to a bubble via the liquid phase motion surrounding the bubble. History forces like the Basset forces are ignored because the shape of the bubble is almost spherical and the vorticity generation at the clean bubble surface is quite low (the history force has not been formulated in a general and reliable form). $\beta$ is the added mass coefficient for a spherical bubble and given by $1 / 2$ [20, $22,24,27,28,29,40,41,47] . D_{L} / D t$ is the substantial acceleration defined by $D_{L} / D t=\partial / \partial t$ 
$+u_{L} . \nabla . V_{G}$ is the volume of a bubble. Since the volumetric change of a bubble due to a pressure fluctuation or to a pressure gradient in the flow field does not affect the translational motion of the bubble, an invariance condition for the bubble volume: $V_{G}=V_{G O}$ is employed. Here, $V_{G O}$ is the initial volume of the bubble. $C_{D}$ is the drag coefficient of a bubble, and the constitution formula for waste water [49] is adopted: $C_{D}$ $\left.=\max \left\{C_{D 1}, C_{D 2}\right)\right\}, C_{D 1}=(24 / R e)\left(1+0.15 R e^{0.687}\right)$, and $C_{D 2}=(8 / 3)[E /(E+4)]$. Here, $R e$ is the bubble Reynolds number defined by: $R e=2$ $r_{G} \rho_{L}\left|u_{s}\right| / \mu_{\mathrm{L}}$, and $E$ is the Eotvos number. $r_{G}$ is the bubble radius, $u_{s}$ is the velocity vector of bubble relative to the liquid. The reason of using the formula for waste water is that contaminations and impurities will concentrate on the bubble interface. In Eq. (8), $C_{L}$ is the lift force for bubbles and is given by the equation of Auton [50, 51].

\section{b) Numerical Analysis and Boundary Conditions}

The governing equations are solved based on the HSMAC (highly simplified marker and cell) algorithm $[20,52]$. The procedures of the calculation were explained in our previous paper [27]. The convection terms are calculated by a 2nd order TVD (total variation diminishing) scheme using the van Leer Limitter [52]. The allowed error of volume fraction for Eq. (3) is 0.000001 for every time step. The initial condition of the flow is a motionless water filling a tank up to $600 \mathrm{~mm}$. As boundary conditions, a non-slip condition is applied to the wall surface, and a constant gas volume flow rate is supplied at the bubble injector. The individual bubble position at the injector is determined randomly. The bubble injection frequency ranges from 10 to 100 per second, and the initial bubble velocity is given as the terminal velocity, which balances buoyancy and drag.
The displacement of the free surface is solved for the following equation of motion based on the height function $\mathrm{h}$ as:

$\frac{\partial h}{\partial t}+U_{L S} \frac{\partial h}{\partial x}=V_{L S}$

where, $U_{L S}, V_{L S}$ are the liquid velocity components in the horizontal and the vertical direction on the surface. $x$ is the horizontal coordinate position. Also, the following stress condition is applied to the surface.

$P_{S}-P=\sigma \frac{\partial^{2} h}{\partial x^{2}}-\mu_{L} \frac{\partial u_{L}}{\partial y}$

Where $P$ is the pressure just under the surface, $P_{S}-P$ is

the additional pressure on the surface, $\sigma$ is the surface tension coefficient, and $y$ is the vertical coordinate. Eq. (10) validly approximates the actual surface motion in case that the gradient of the surface is less than 10 degree. Droplet generation and surface tension waves are ignored since their energy is much smaller than the total energy of the surface flow.

\section{SIMULATION RESULTS OF VELOCITY PROFILE OF THE SURFACE FLOW}

Figure 3 (b) shows a comparison between the numerical and experimental results for the time averaged velocity profiles of the surface flow induced by the bubble plume. In the numerical results, the deviations of the bubble radius are also considered. The surface flow consists of an acceleration process, a gradual damping process, and a rapid damping process near the wall. The qualitative characteristics of the experimental and numerical results for these processes agree well. In every case, the surface velocity downstream of $\mathrm{x}=0.25 \mathrm{~m}$ agrees with the experiments within $5 \%$ of relative error.

Figure 11 shows the numerical simulation of the maximum surface velocity $\mathrm{U}_{\text {smax }}$ with gas flow rate $\mathrm{Q}_{\mathrm{g}}$ and bubble radius dependency. It 
is clear that as the gas flow rate increases the maximum surface velocity $U_{\text {smax }}$ increases. The power indexes of the gas flow rate and the bubble diameter for the maximum surface velocity are calculated using the numerical result data based on a least square method (LSA). The resulting power index of the gas flow rate is about 0.50 .

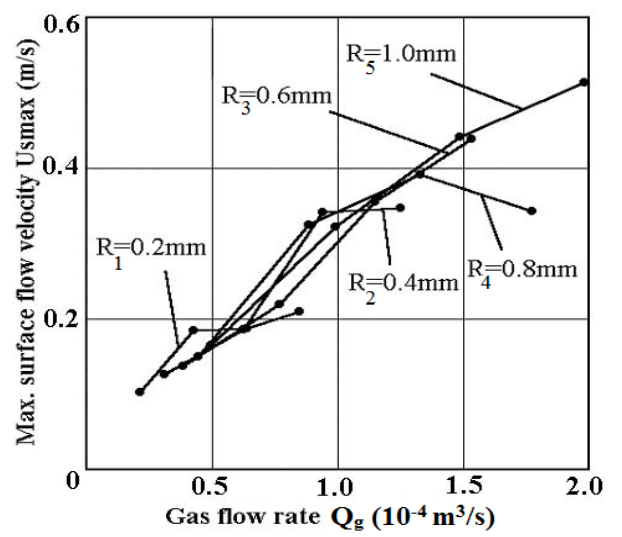

Fig. 11. Numerical results of the relationship between maximum surface flow velocity and bubble generation conditions

On the contrary, the power index of the bubble diameter for the surface flow velocity is about -0.4 . These numerical results show good analogy with the experimental results, and confirm that the point at which the horizontal velocity has a local maximum value depends on the bubble size. However, more details explanation should be accumulated.

\section{THE NUMERICAL RESULTS OF THE INTERNAL FLOW STRUCTURE}

The two-dimensional flow structures are explained and analyzed by numerical simulation based on the Eulerian-Lagrangian model in order to clarify the difference of qualitative features among four types of flow fields. Figures 12 (a) and (b), show the timeaveraged liquid velocity distributions near the top interface for the case of a bubble plume, while Figs. 12 (c) and (d) show the timeaveraged liquid velocity distribution near the top interface for the case of a single-phase vertical liquid jet. Since the averaged flow field is symmetric, only a half domain is drawn. In the case of a bubble plume consisting of small bubbles, a rapid distortion results near the free surface where the main upward liquid flow changes its orientation into a horizontal flow just under the free surface as shown in Fig. 12 (a). However in the case of large bubbles, this does not occur near the free surface because of the wide pumping effect. This result is similar to that obtained by the experimental results and confirms the fact that smaller bubbles induce faster surface flow velocities. Figures 12 (c) and (d) show the time-averaged velocities in case where a single-phase vertical liquid jet flow is applied. The jet flow velocity is set ranging from $0.5 \mathrm{~m} / \mathrm{s}$ to $1.5 \mathrm{~m} / \mathrm{s}$, which is approximately equivalent to the liquid velocity, induced by the bubbles. It is recognized that the flow pattern is essentially different from that of the bubble plume. In case of liquid jet: 1) In the vertical direction the liquid velocity is not accelerated but rather dissipated due to the viscosity. 2) Liquid velocity just near th e free surface is not sufficient to cause a high speed surface flow. 3) The rapid distortion region of the liquid phase is not clearly distinguished. These results indicate that the surface flow is more effectively generated by bubbles than by a liquid jet flow. However, the results obtained by numerical prediction and those obtained by PIV measurements for the bubble plume show good analogy.

Fig. 13 shows the numerical results of comparison between the cases of a free surface (a) and the case that the surface is covered by a solid film (b) (considering this film is thin enough and disregarding its mass).

It is clear that the surface flow is generated in the vicinity of the free surface and that the upward flow changes its orientation under the free surface from vertical into horizontal in 
the case of the free surface. But this does not happen in the case with a surfactant because the stress condition of the surface is different.

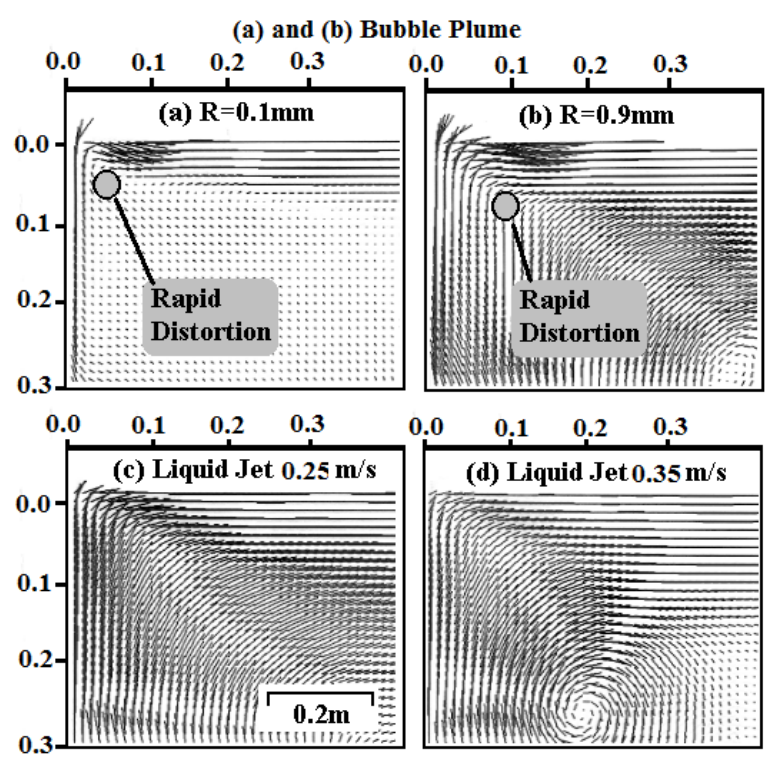

Fig. 12. Distortion of liquid flow near the free surface [In case (a), (c) $U_{\text {smax }}=0.25 \mathrm{~m} / \mathrm{s}$, in case (b), (d) $U_{\text {smax }}=0.35 \mathrm{~m} / \mathrm{s}$. $(\mathrm{x}<0.16 \mathrm{~m}, \mathrm{y}<0.10 \mathrm{~m})]$
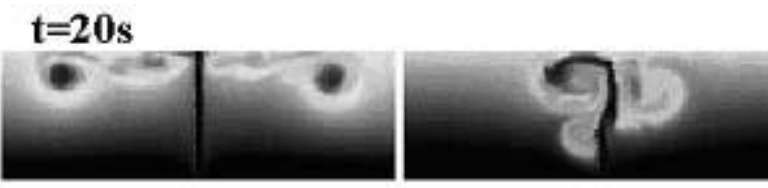

$\mathrm{t}=40 \mathrm{~s}$

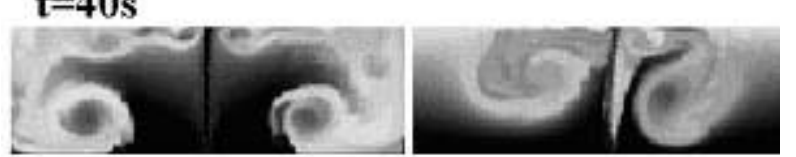

$\mathrm{t}=60 \mathrm{~s}$

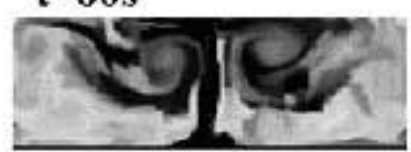

(a) Free surface

(b) Surfactant surface

Fig. 13. Comparison of free surface and non-slip interface cases

However in case (b), the following points are important: 1) The frictional resistance affects the flow in the tangent direction of surface, but does not affect displacement in the vertical direction. 2) The bubbles reach the surface and spout against the film. Hence, the liquid flow which is driven by the rising bubbles reaches the surface with its maximum momentum and is then strongly reflected and returned back downward into the tank at a very sharp angle. 3) A surface flow does not accrue in the vicinity of the surface, and the convection scale is very small. 4) Large vorticity results in the surface, but the momentum is scattered and lost inside the bubble plume in the vicinity of surface. 5) The high shear stress on the surface greatly affects the convection that is induced by the bubble plume, whereas the inner flow is affected by boundary condition. This phenomenon is completely different from natural convection. Hence, no wide surface flow is induced in case (b).

\section{CONCLUSION}

The detailed structure of the surface flow generation process induced by a bubble plume is investigated by numerical simulation depending on Eulerian-Lagrangian model and by using flow visualization and image processing including the PIV measurements. The measurement of the averaged surface flow velocity is introduced in detail, and the twodimensional behavior is measured. The flow structure is sensitively modulated by the bubble generation conditions (gas flow rate and bubble size). The experimental results and the numerical results show good analogy and the main results can be summarized as follows:

1- The velocity of the surface flow induced by the bubble plume in the vicinity of the free surface is larger and stronger than that in other regions. Moreover, the surface flow is particularly rapidly generated in the vicinity of the free surface. The maximum surface velocity increases with the gas flow rate at a power index of around 0.25 to 0.50 . The increase of the surface flow velocity responds to the increase of liquid volume flux pumped by the bubbles. Moreover, the power index of the bubble diameter for the maximum surface flow velocity ranges from -0.75 to -0.25 . 
Hence, the surface flow velocity increases with the gas flow rate. Also, it is remarkably enhanced when smaller bubbles are generated. The results indicate that the smaller the bubbles the faster the induced surface flow velocity.

2- The width of the upward flow induced by the bubble plume is larger than the thickness of the surface flow.

3- The highest kinetic energy is generated in the center of the bubble plume and in the area of the surface flow where the flow changes its orientation from the vertical into the horizontal direction. This implies that the surface flow induces the largest kinetic energy. This observation confirms the fact that the bubble plume can generate a strong and wide surface flow over the bubble generation system.

4- High vorticity distribution, high shear strain rate and high shear stress rate are generated by the surface flow, which induced by the bubble plume, and these phenomena appear in a layer under the free surface. In this layer the liquid flow rapidly changes its orientation from the vertical to the horizontal direction. Therefore, it can be said that the initial surface flow is rapidly generated in this layer. Therefore, the rapid distortion of the liquid phase results just under the free surface. This is qualitatively different from (not found so clearly in) the case of a single-phase liquid jet flow whose speed is equivalent to the bubble plume. These results indicate that a surface flow is more effectively generated by means of bubbles than by a liquid jet flow because the distortion point appears in the vicinity of surface. On the other hand, the surface flow is not induced widely in case that the free surface is covered by a solid film.

\section{REFERENCES}

[1] Taylor G. I., "The Action of a Surface Current Used as a Breakwater", Proc. Roy. Soc. A231, 1955, pp. 466-478.

[2] Jones W. T., "Air Barriers as Oil-Spill Containment Devices", J. Soc. Pet. Eng., 1972, pp. 126-142.

[3] Marks, C. H., and Cargo D. G., "Field Tests of Bubble Screen Sea Nettle Barrier", J. Mar. Tech, 1974, pp. 33-39.

[4] Mcdougall T. J., "Bubble Plume in Stratified Environments", J. Fluid Mech., Vol. 85 (4), 1978, pp. 655-672.

[5] Hara, S., Igai, M., and Namie S., "Fundamental Study on Air Bubble Type of Oil Fence", J. Kansai Ship-making Society, Vol. 186, pp. 133-138.

[6] Hara S., Ikai M. and Namie S., "Fundamental Study on an Air Bubble Type of Oil Boom", Trans. Ship-Making Society of Kansai-Japan, Vol. 194, 1984.

[7] Sheng Y. Y., and Irons G. A., "Measurements of the Internal Structure of Gas-Liquid Plumes", Metallurgical Trans., Vol. 23-B, 1992, pp. 779-788.

[8] Iguchi M., Takehuchi H. and Morita Z., "The Flow Field in Air-Water Vertical Bubbling Jets in a Cylindrical Vessel", ISIJ International J., Vol. 31 ( 3), 1991, pp. 246-253.

[9] Tomiyama A., Uegomori S., Minagawa H., Fukuda T. and Sakaguchi T., "Numerical Analysis of Bubble-Induced Natural Circulation based on Multidimensional Two-Fluid Model", Trans. JSME (Japan. Soc. Mech. Eng.), 1994, B, pp. 60-580, pp. 9-14.

[10] Abdulmouti H., Murai Y., Ohno Y. and Yamamoto F., "Measurement of Bubble Plume Generated Surface Flow Using PIV", Journal of the Visualization Society of Japan, Vol. 21 (2), 2001, pp. 31-37.

[11] Gross R. W. and Kuhlman J. M., "ThreeComponent Velocity Measurements in a Turbulent Recirculating Bubble-Driven Liquid Flow", Int. J. Multiphase Flow, Vol. 18, 1992, pp. 413-421.

[12] Sun T. Y. and Faeth G. M., "Structure of Turbulent Bubbly Jets-I. Methods and Centerline properties", Int. J. Multiphase Flow, Vol. 12, 1986 a, pp. 99-114. 
[13] Sun T. Y. and Faeth G. M., "Structure of Turbulent Bubbly Jets-II. Phase Property profiles", Int. J. Multiphase Flow, Vol. 12, 1986 b, pp. 115-126.

[14] Hussain N. A. and Narang B. S., "Simplified Analysis of Air-Bubble Plumes in Moderately Stratified Environments", ASME. Journal of Heat Transfer. Vol. 106, 1984, pp. 543-551.

[15] Chesters A. K., Van Doorn M. And Goossens L. H. J., "A General Model of Unconfined Bubble Plumes from an Extended Source", Int. J. Multiphase Flow, Vol.6, 1980, pp. 499-521.

[16] Abdel-Aal H. K., Stiles G. B. and Holland C. D., "Formation of Interfacial Area at High Rates Gas Flow Through Submerged Orifices", AICHE J., Vol. 12, 1966, pp. 174-180.

[17] Hussain N. A., Siegel R., "Liquid Jet Pumped by Rising Gas Bubbles", J. Fluids Eng., March 1976, pp. 49-61.

[18] Milgram J. H., "Mean Flow in Round Bubble Plumes", J. Fluid Mech., Vol. 133, 1983, pp. 345-376.

[19] Leitch A. M. and Baines W. D., "Liquid Volume Flux in a Weak Bubble Plume", J. Fluid Mech. Vol. 205, 1989, pp. 77-98.

[20] Murai Y. and Matsumoto Y., "Numerical Analysis of Detailed Flow Structures of a Bubble Plume", JSME International Journal, Series B, Vol. 41(3), 1998, pp. 568-575.

[21] Fanneløp T. K., Hirschberg S., Kuffer J., "Surface Current and Recirculating Cells Genelated by Bubble Curtains and Jets", J. Fluid Mech. Vol. 229, 1991،pp. 629-657.

[22] Hassan Abdulmouti, "The Flow Patterns in Two Immiscible Stratified Liquids Induced by Bubble Plume", The International Journal of fluid Dynamic, Vol. 6, Article 1, 2002.

[23] Hassan Abdulmouti, "Visualization and Image Measurement of Flow Structures Induced by a Bubbly Plume", Ph. D. thesis, Fukui University, 2003.

[24] Murai Yuichi, Ohno Yasushi, Abdulmouti Hassan, Yamamoto Fujio, "Flow in the Vicinity of Free Surface Induced By a Bubble Plume", JSME. Vol. 67(657), B, 2001.

[25] Alam M., Arakeri V. H., "Observations on Transition in Plane Bubble Plumes", J. Fluid Mech., Vol. 254. 1993, pp. 363-374.
[26] Iguchi M., Kondoh T., Uemura T., "Simultaneous Measurement of Liquid and Bubble Velocities in a Cylindrical Bath Subject to Centric Bottom Gas Injection", Int. J. Multiphase Flow, Vol. 20 (4), 1994, pp. 753-762.

[27] Murai Y et. al., "The Structure of Disorder Reverse Energy Cascade in Bubbly Flow", Trans. JSME B. 65-632, 1999, pp. 169-176.

[28] Murai Y. and Matsumoto Y., "Eulerian Analysis of Bubbly Two-Phase Flows Using CIP Scheme", Computational Fluid Dynamics Journal", Vol. 8 (1), April, 1999.

[29] Matsumoto Y. and Murai Y., "Numerical Simulation of Bubble Plume in a Tank with Free Surface", Trans. Jpn. Soc. Mech. Eng., Vol. 61( 588), B., 1995, pp. 54-61.

[30] Durst F., Schonung B., Selanger K. and Winter M., "Bubble Driven Liquid Flows", J. Fluid Mech., Vol. 170, 1986, pp. 53-82.

[31] Hirt C. W., Cook J. L., "Calculating ThreeDimensional Flows around Structures and over Rough Terrain", J. Computational Physics., Vol.10, 1972, pp. 324-340.

[32] Yamamoto F., Wada A., Iguchi M., Ishikawa M., "Discussion of the Cross-Correlation Methods for PIV.", J. Flow Visualization and Image Processing, Vol. 3, 1996, pp. 65-78.

[33] Uemura T., Yamamoto F. and Ohmi K., "A High Speed Algorithm of Image Analysis for Real Time Measurement of Two-Dimensional Velocity Distribution", ASME FED. Vol. 85, 1989, pp. 129-133.

[34] Uemura T., Yamamoto F., Koukawa M., "High Speed Algorithm for Particle Tracking Velocimetry Using Binary", J. of the Visualization Society of Japan, Vol. 10-38, 1990, pp. 196-202.

[35] Baines W. D. and Leitch A. M., "Destruction of Stratification by Bubble Plume", Journal of Hydraulic Engineering, Vol. 118 (4), 1992, pp. 559-577.

[36] Ido T., Ishikawa M., Murai Y., Yamamoto F., "PIV Measurement of Torque Converter Internal Flow-Improvement of PIV Result using CFD Technique", Proc. of the $3^{\text {rd }}$ Int. Conference on Fluid Dynamic Measurement and its Applications, Beijing, 1997, pp. 155-160.

[37] Murai Yuichi, Ido Takehiro, Ishikawa Masa-aki Yamamoto Fujio, "Development of the PostProcessing Method for PIV Measurement Result 
Using Computational Fluid Dynamics Procedure", Transaction of the Japan Society of Mechanical Engineers, Vol. 64B-626, 1998, pp.109-116.

[38] Shimada N., Tomiyama A., "3D Multi-field Simulation of Bubbly Flow", Prof. Asian Symp. Multiphase Flow (ASMF'99). Edit. Ohba K., 1999, pp. 51-56.

[39] Tomiyama A et. al., "The Numerical Simulation of Natural Circulative Bubbly Flow is Based on Miltidimensional Two Fluid Model", Trans. JSME B, Vol. 60-580, 1994, pp. 3987-3993.

[40] Matsumoto Y., Murai Y., "The Numerical Simulation of Bubble Plume in Container Have Free Surface", Trans. JSME B, Vol. 61-588, 1995, pp. 2818-2825.

[41] "Bubbling Convection Patterns in Immiscible Two-phase Stratified Liquids", International Journal of Heat Exchangers (IJHEX). Vol. 7 (1), ISSN 1524-5608, June, 2006, pp. 123-143.

[42] Namie S., Hara S., Ikai M., "The Simulation of Two-Dimensional Bubbly Buoyant Jet Flow Motion in the Equable Horizontal Flow", Trans. JSME B, Vol. 51-463, 1985, pp. 847-855.

[43] Morinaga E., Ayukawa K., Oti J., Kwara G., "The Numerical Simulation in Flow Near the Bubble Group", Trans. JSME B, Vol. 63-609, 1997, pp. 1489-1495.

[44] Nihei Y., Nadaoka K., "The Numerical Simulation of Dispersed Two-Phase Turbulent Flow based on GAL-LES Model (About the Plane Bubble Plume", Trans. JSME B, Vol. 64-619, 1998, pp. 684-692.

[45] Nadaoka K., Nihei Y., Yagi H., "Grid-averaged Lagrangian LES Model for Multiphase Turbulent Flow", Int. J. Multiphase Flow, Vol. 25, 1999, pp. 1619-1643.

[46] Tomiyama A., Higaki J., Zun I., Sou A., Sakaguti T., "The Numerical Simulation of Dispersed Multi-Phase Flow based on Particle Trace Method (The First Report)", Trans. JSME B, Vol. 62-599, 1996, pp. 2558-2564.

[47] Murai Y., Matsumoto Y., Sou K., Yamamoto F., "The Numerical Simulation of Disorder Structure Formed by Bubbly Buoyant Force", Trans. JSME B, Vol. 64-626, 1998, pp. 32573262.

[48] Batchelor G.K., An Introduction to Fluid Dynamics, C. U. Press, 1967, pp. 254-255.
[49] Tomiyama A et. al., "The Research About Bubbly Drag Coefficient (The First Report: Drag Coefficient of a Single Bubble in Standstill Liquid)", Trans. JSME B, Vol. 61-587, 1995, pp. 2357-2364.

[50] Auton T. R., "The Lift Force on a Spherical Body in a Rotational Flow", J. Fluid Mech., Vol. 183, 1987, pp. 199-212.

[51] Auton R., Hunt J. C. R., Prudhumme M., "The Force Exerted on a Body in Inviscid Unsteady Non-uniform Rotational Flow", J. Fluid Mech., Vol. 197, 1988, pp.241-257.

[52] Okano T., Sugawara S., "High Resolution Two Phase Flow Analysis using Second-Order TVD Schemes", Proc. Int. Conf. Multiphase Flow'91Tsukuba, 1991, pp.303-308. 


\section{آلية تكوين التدفق السطحي المولا بواسطة حزمة الفقاعات حسان عبدالمعطي \\ قسم الهندسة الميكانيكية، كلية الهندسة، جامعة الأمير محمد، المملكة العربية السعودية}

(الملخص:

لقد استخدمت تقنية تطبيق التدفق السطحي المولد بواسطة حزمة الفقاعات كواحدة من الطرق الفعالة للتحكم بالمو اد الطافيه على السطح و لجمعها وذللك في الاجهزة البحرية، البحيرات، البحار ، الانهار ، المحيطات وكذلك في كثير من التطبيقات الهندية والصناعية التي تستثمر وتتعامل مع السطح الحر. على أي حال لم يتم قياس وتوضيح ودراسة أليه عمليات التذفق السطحي المولد بالتفصيل في الماضي. لذلك فان الحافز الأساسي لهذا البحث هو المطلب الكبير لمعرفة الصفات الرئيسية و الملامح الأساسية للتدفق السطحي والذي يعتمد بشكل أساسي على نسبة تدفق وغزارة الغاز، حجم الفقاعات وتأثير ها، وتدفق كلا الطورين الداخلي لحزمة الفقاعات. تم الاعتماد على تحليل التنفق ثنائي الأبعاد بالاعتماد على نموذج (Eulerian-Lagrangian) وكذلك قياس سر عة تتبع أثر الجزيئات من أجل توضيح ألية عمليات التدفق السطحي بالتفصيل.

لقد كثفت النتائج الحالية أنه يمكن استنتاج وحساب مخطط سرعه السطح وذللك باستخدام نموذج مع توافق ونطابق جيدين مع النتائج المخبرية. تزداد السرعة العظمى للتدفق (Eulerian-Lagrangian) السطحي عندما يتم تزويد فقاعات ذات حجم صغير. يتم توليد التنفق السطحي بفاعلية وكفاءة عالية في حالة استخدام حزمة الفقاعات مقارنة مع استخدام تدفق السائل النافوري وذللك كون نقطة ومنطقة التثوه نظهر قرب السطح الحر في حالة حزمة الفقاعات. تم الحصول على النتائج و الحسابات بو اسطة التصوير (التنثيل) لمنطقتين: الاولى للمنطقة العلوية للسطح للتنفقي و والثانية لمنطقة توليد التدفق السطحي تحت السطح الحر. 